\title{
Aurelio González, México tradicional, Literatura y costumbres, Ciudad de México, El Colegio de México, Centro de Estudios Lingüísticos y Literarios, 2016, $387 \mathrm{pp}$.
}

Stecher, Cecilia

Instituto de Investigaciones en Humanidades y Ciencias Sociales (IdIHCS) - Universidad Nacional de La Plata -CONICET, Argentina

Cita sugerida: Stecher, C.(2018). [Revisión del libro México tradicional, Literatura y costumbres por A. González]. Olivar, 18 (27), e030. https://doi.org/10.24215/18524478e030

(c) (i) Esta obra está bajo licencia Creative Commons Atribución-NoComercial-CompartirIgual 4.0 Internacional http://creativecommons.org/licenses/by-nc-sa/4.0/deed.es_AR 


\title{
Aurelio González, México tradicional, Literatura y costumbres, Ciudad de México, El Colegio de México, Centro de Estudios Lingüísticos y Literarios, 2016, 387 pp.
}

\author{
Cecilia Stecher \\ Instituto de Investigaciones en Humanidades y Ciencias \\ Sociales (IdIHCS) - Universidad Nacional de La Plata - \\ CONICET, Argentina
}

Aurelio González nos presenta México tradicional, literatura y costumbres editado por el Colegio de México en el 2016. Como tema principal abarca la literatura tradicional en relación con la cultura y las costumbres de un país como es el de México. En este sentido, subdivide los temas en los diferentes géneros y tópicos populares existentes en el México actual desde los tiempos de la conquista y la preconquista con lo español y lo de los pueblos originarios.

Reúne en este compilado tres grandes categorías que conforman el sentido de lo mexicano, por un lado el análisis de los corridos, los romances, los cuentos y leyendas; por otro las fiestas populares como el carnaval, el Día de los Muertos, Semana Santa y la Navidad; y por último los símbolos tradicionales de la zona como el gallo, el caballo y la pistola. Retoma, de este modo, la importancia de ciertos personajes existentes en la literatura popular como la llorona, la mujer infiel, que tiene su representación en romances, corridos y cuentos, entre otros. En este sentido, recupera también el rol de la mujer dentro de la jerarquía familiar y cuentista, la importancia de los bailes en relación con las historias que se narran y con las canciones líricas y/ o narrativas existentes en la zona de México.

González hace un interesante relevamiento de la relación entre la literatura hispánica traída por la conquista y la tradición de los pueblos originarios tanto en rituales como en las historias y las creencias religiosas de los mismos; por ello en distintas zonas se dan diferentes tipos de fiestas en diferentes períodos del año, y se realiza, en este libro, un apartado dividiendo aquellas fiestas según su ubicación geográfica. En el caso de México este se divide en cinco grandes espacios, además del México Central, que se reconoce como el resultado de la "conformación radial" que ha marcado México geográfica, histórica y urbanísticamente hablando. Estas otras zonas son la Vertiente del Golfo, la Vertiente del Pacífico, la Vertiente del Norte, la Cadena Centroamericana, y la Cadena Caribeña.

En su primer apartado "cuentos tradicionales" Aurelio González retoma el concepto de tradición y hace referencia a que "la literatura general, no solo la culta, es muy útil para comprender algunos mecanismos de construcción de identidades culturales" (19). Partiendo desde este concepto compara la tradición cuentística europea con la tradición indígena de la zona, realiza una breve clasificación sobre los tipos de cuentos existentes según la temática que abordan como "cuentos de animales", "cuentos maravillosos", "cuentos de costumbres", entre otros. Estos nombrados anteriormente conforman el corpus de los cuentos tradicionales, diferente a la clasificación de los cuentos indígenas que realiza a continuación en el libro, donde explica que la manera de transmitir estos relatos son a través de "complejas narraciones míticas que describen extrañas cosmogonías, cuentos y leyendas en los que la realidad convive con la maravilla” (40), y es por ellos difícil desligar y clasificar una anécdota de un cuentos o un relato de una leyenda en una sociedad que no diferenciaba de este modo su propia tradición.

En este mismo apartado González nos expone una imagen del “cuentero" figura oficial del recitado de cuentos tradicionales, más allá de su narración en los ámbitos familiares, y lo compara con otras figuras de Latinoamérica en donde aparece esta figura oficial que relata, como su existencia en los velorios cubanos, o 
los existentes en la zona de Chiapas y también retoma la figura del gaucho en las pulperías de las pampas argentinas.

Su segundo apartado se titula "Canciones y bailes" pero primero retoma el concepto de poesía lírica y sus características principales. Subdivide en tres subapartados donde diferencia las canciones y las actividades que se desarrollan en torno a ellas, las canciones líricas y las canciones narrativas existentes en el mundo mexicano y luego relaciona el baile con las canciones. Aquí clasifica las canciones según su género como la canción ranchera, el bolero, la cantilena, la trova, entre otras. Luego de esta división realiza otra clasificación en tipos de canción lírica como la copla, los villancicos, las canciones infantiles, o según el tipo de canción narrativa como el corrido, el romance, las mañanitas y las décimas. Este tipo de canciones las recupera para definir el lugar geográfico de México más los transmisores de esto géneros como son los mariachis, los conjuntos de son y los improvisadores que realiza un trovador.

El tercer apartado "Corridos y romances" se resalta la importancia de la literatura oral para el pueblo mexicano que la difunde de manera constante, entre ellas los géneros más reconocidos son la balada, los romances y los corridos, estos últimos originados en la Revolución mexicana con los bandoleros y las pistolas, donde cumplían una función noticiera y un sentido épico con los personajes de la época. En este apartado retoma los tres grandes símbolos de la Revolución y de México como lo son el gallo, la pistola y el caballo.

El cuarto apartado "Fiestas, conmemoraciones y sus textos" clasifica primeramente el tipo de fiesta según su lugar geográfico, cada zona tiene sus propias costumbres y celebraciones que se diferencia con otras. Los textos que acompañan estas fiestas van acordes a las fechas, como las coplas de Dios en Pascuas, los villancicos en Navidad, las denominadas "calaveras" que son poemas humorísticos que se recitan en los cumpleaños o celebraciones familiares o también las canciones o refranes sobre la muerte que se dan en dichos momentos de pérdida. En este punto resalta la importancia del carnaval tradicional en las diferentes zonas de México como el de Autlán (Jalisco), el de Tlaxcala, el de Huejotzingo, entre otros; también se da cuenta de la celebración de la Semana Santa, la pascua cristiana, con el Domingo de Ramos y el Jueves Santo además del “altar de los dolores" donde se colocan plantas germinadas en macetas con forma de animales que representan la Eucaristía y el nacimiento de la fe.

Este mismo apartado resalta la conmemoración de Día de Muertos ya que en México este momento de la vida se celebra y se la toma como un paso más en el existir humano. Para González y los mexicanos la muerte se vuelve "jocosa e irónica" y a la personificación de la muerte la llaman "calaca, huesuda, dientona, la flaca, la parca o hasta la catrina” (207). Para explicar esta celebración el autor retoma el concepto de cultura popular y retoma la importancia de los contextos culturales existentes que influyen en la realización de esta manifestación. El "altar de muertos" es la base de donde parte esta celebración, donde se coloca las fotos de los seres queridos para que no sean olvidados junto con ofrendas y flores que se esparcen junto al altar y la casa para que el alma del difunto pueda seguir el camino hasta su altar familiar.

En el libro se expone también un quinto y sexto apartado sobre las leyendas y las costumbres mexicanas que conforman, junto con la poesía y la fiesta, la identidad del pueblo mexicano. Dentro de las costumbres coloca un capítulo que habla de las artesanías y las manualidades como una trasmisión de lo tradicional, esto incluye las piñatas hechas para la Rosca de Reyes, los vestidos y las máscaras de carnaval, las matracas y las "judas" para Semana Santa y las Catrinas, los entierros y las calaveras de azúcar hechas para el Día de los Muertos. Estas fiestas son definidas por el autor como "el tiempo y las pasiones" que se dan en la relación con los movimientos astronómicos, los cambios de clima y de estaciones y también con los tiempos de la Iglesia Católica. Aurelio González divide en tres tipos las fiestas tradicionales: las primeras son las correspondientes con la Iglesia Católica, los días de los santos, la vida, nacimiento y muerte de Cristo o la de la Virgen; en segundo lugar, se encuentran las fiestas civiles, organizadas por el Estado; y por último lugar nombra las celebraciones privadas como las bodas y los entierros.

En el anexo Aurelio González recupera una vasta cantidad de ejemplos de lo estudiado: los cuentos, las leyendas, las canciones, los romances, los corridos, los romances y las canciones infantiles, dejando en 
claro una exhaustiva investigación y reconocimiento cultural que plasma en este módico libro. Su modo de escritura nos deja observar un reconocido conocimiento sobre la cultura y la literatura mexicana al mismo tiempo que teoriza estos conocimientos y los compara con los existentes en España y el resto de Latinoamérica. 